\title{
ANALISIS DAN PERANCANGAN SISTEM INFORMASI PEMETAAN POTENSI EKONOMI KEWILAYAHAN DI KOTA BANDUNG
}

\author{
Yusup Jauhari Shandi \\ Sekolah Tinggi Manajemen Informatika dan Komputer LIKMI \\ J1. Ir. H. Juanda no 96 Bandung \\ ujshandi@gmail.com
}

\begin{abstract}
ABSTRAK
Kota Bandung saat ini menjadi kota yang banyak diminati oleh para wisatawan baik domestik maupun mancanegara karena daya tarik akan keindahan alam, bangunan heritage, kuliner, destinasi budaya dan kesenian serta bidang fashion yang menjadikan kota Bandung sebagai Paris van Java.

Bidang pariwisata menjadi peluang besar Kota Bandung untuk meningkatkan pendapatan daerah. Sistem pemetaan potensi ekonomi yang dimiliki oleh kota bandung per kecamatannya diharapkan mampu menjadi alat pendukung dalam hal penyampaian informasi kepada wisatawan khususnya dan masyarakat pada umumnya agar mengenal lebih banyak lagi potensi ekonomi beserta wilayah atau lokasinya.
\end{abstract}

Kata kunci : potensi, ekonomi, pariwisata, pemetaan

\section{PENDAHULUAN}

Kota Bandung merupakan salah satu kota di Jawa Barat yang dikenal sebagai Kota Kreatif. Terdapat banyak pelaku ekonomi kreatif berbagai produk yang menarik, memiliki value added tinggi dan berdaya saing sehingga dapat bersaing di pasar lokal, nasional maupun internasional. Hal tersebut mengantarkan Kota Bandung sebagai UNESCO Creative Cities Network yang dinobatkan oleh UNESCO salah satu organisasi PBB bidang pendidikan, keilmuan dan kebudayaan. Capaian tersebut merupakan hasil kolaborasi antara pemerintah, bisnis, komunitas masyarakat dan semua stakeholder yang terlibat.

Kota Bandung terbagi menjadi 30 Kecamatan diantaranya Kecamatan Andir, Antapani, Arcamanik, Astana Anyar, Babakan Ciparay, Bandung Kidul, Bandung Kulon, Bandung Wetan, Batununggal, Bojongloa Kaler, Bojongloa Kidul, Buahbatu, Cibeunying Kaler, Cibeunying Kidul, Cibiru, Cicendo, Cidadap, Cinambo, Coblong, Gedebage, Kiara Condong, Lengkong, Mandalajati, Panyileukan, Rancasari, Regol, Sukajadi, Sukasari, Sumur Bandung, dan Ujung Berung. Setiap Kecamatan memiliki potensinya masingmasing. Hal tersebut merupakan peluang besar Kota Bandung untuk meningkatkan pendapatan daerah melalui peningkatan value produk-produk wisata, kuliner maupun fashion dalam mengembangkan bisnis berbasis potensi lokal.

\section{POTENSI EKONOMI KOTA BANDUNG}

Untuk mengukur potensi ekonomi di suatu wilayah terdapat tiga metode yaitu: 
a. Regional Account (Income - Expenditure) Approach yang mengukur nilai ekonomi dari suatu wilayah berdasarkan produk atau kegiatan ekonomi pada setiap sektor di suatu wilayah.

b. Input - Output Approach: yang mengukur kegiatan ekonomi di suatu wilayah dari nilai pemanfaatan faktor produksi atau input baik yang tersedia di wilayah tersebut maupun yang berasal dari wilayah lain untuk menghasilkan output tertentu.

c. Economic Base Approach yaitu dengan mengukur nilai produksi, aktivitas ekonomi dan pertumbuhan setiap sektor ekonomi sehingga menghasilkan kelompok struktur perekonomian daerah menjadi sektor unggulan dan bukan unggulan.

Hasil sensus ekonomi Kota Bandung tahun 2016 yang dikeluarkan oleh Badan Pusat Statistik (BPS) Kota Bandung menyebutkan bahwa potensi ekonomi Kota Bandung adalah :

a. Sumber daya manusia yang melimpah sebagai penggerak ekonomi

b. Perekonomian Kota Bandung cukup stabil dalam 5 tahun terakhir

c. Penggerak utama perekonomian Kota Bandung

Perdagangan merupakan salah satu sektor perekonomian di Kota Bandung yang mendapat perhatian khusus dari Pemerintah Kota Bandung. Beberapa program dalam sektor perdagangan dituangkan dalam Rencana Pembangunan Jangka Menengah Daerah (RPJMD) Kota Bandung untuk mendorong sektor ini dalam rangka meningkatkan perekonomian Kota Bandung.

Informasi dan komunikasi menjadi kebutuhan yang sangat penting dirasakan oleh masyarakat. Oleh karena itu, dukungan yang cukup besar dari pemerintah Kota Bandung menyebabkan tumbuh pesatnya kategori informasi dan komunikasi. Hal tersebut dapat diamati dari laju pertumbuhan ekonomi

\section{ANALISA DAN PERANCANGAN SISTEM}

Kebutuhan data spasial untuk batas administrasi berdasarkan kecamatan di kota Bandung diambil dari http://data.bandung.go.id/ dalam format GeoJSON. Untuk peta dasarnya menggunakan layanan dari https://www.openstreetmap.org . Berikut adalah design tampilan ketika area sebuah kecamatan di klik maka akan mucul informasi :

\section{a. DATA KEWILAYAHAN}

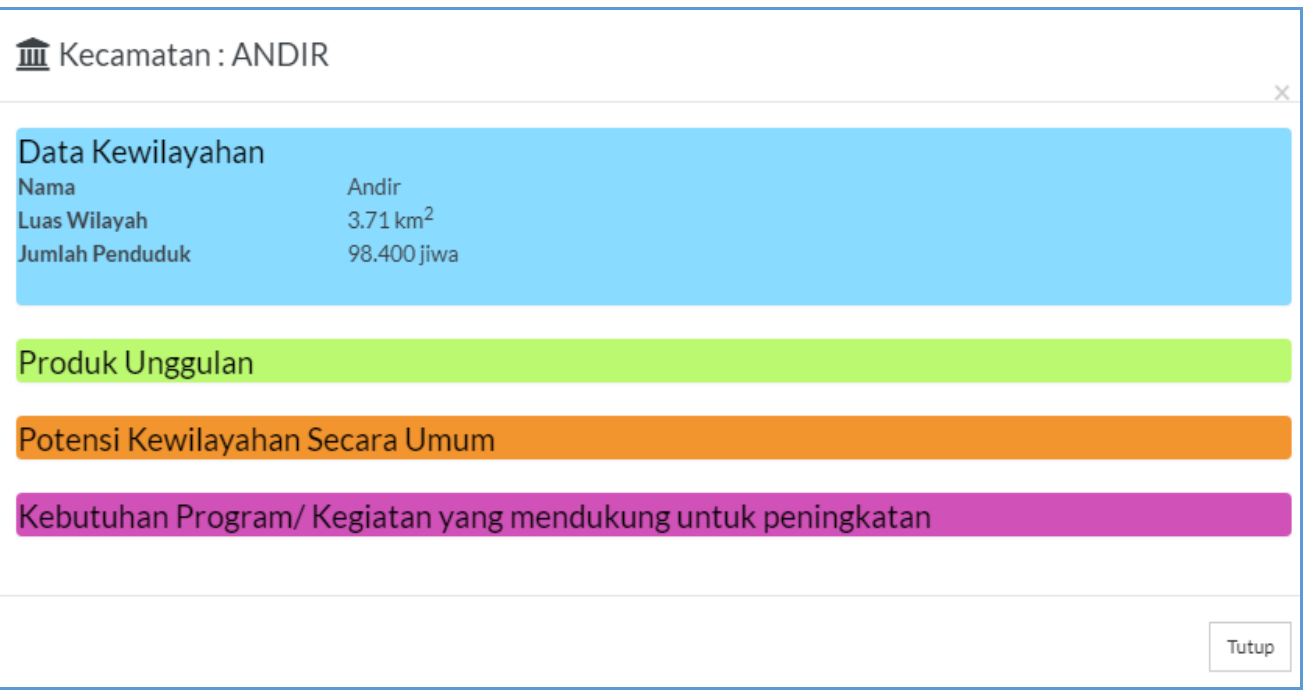

Gambar 1

Data Kewilayahan 


\section{b. PRODUK UNGULAN}

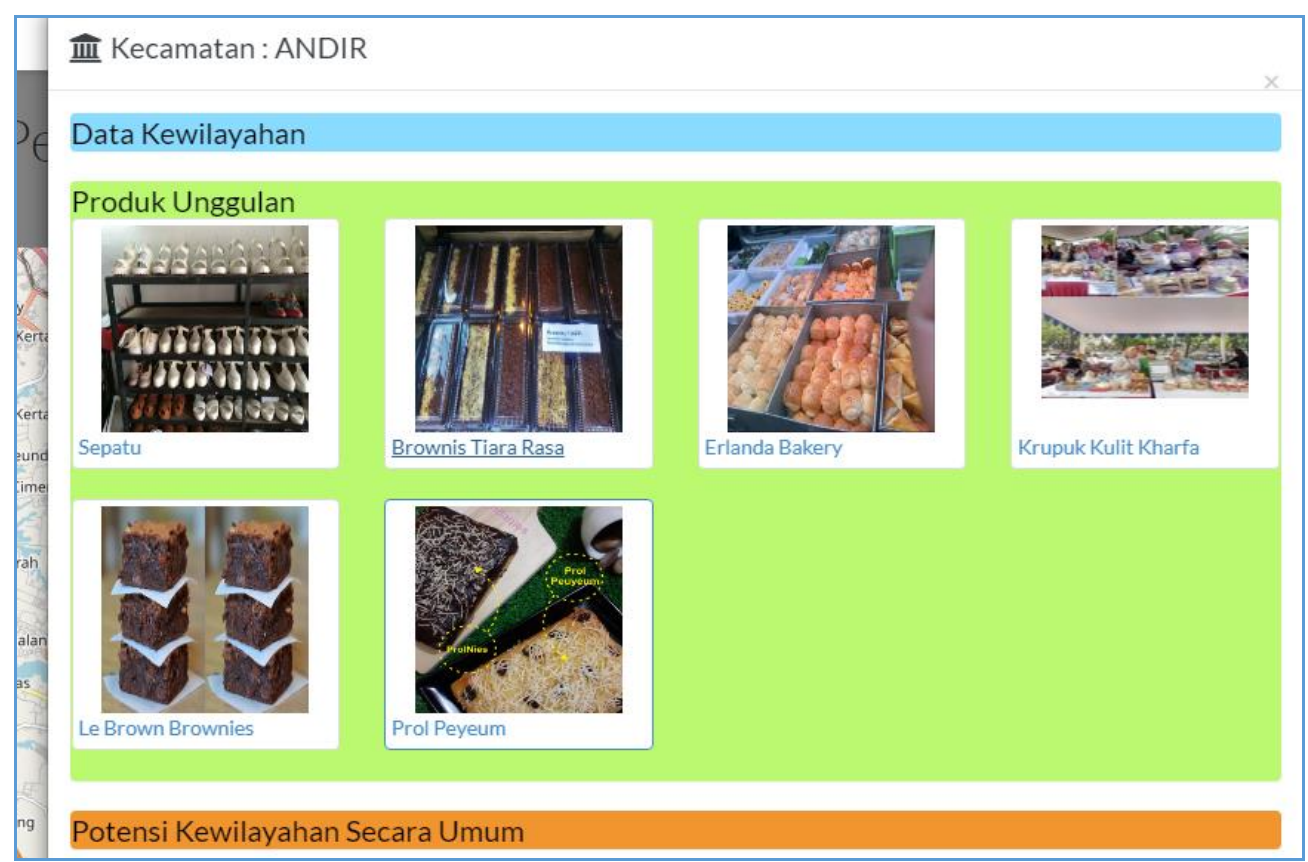

Gambar 2

Produk Unggulan

\section{c. POTENSI KEWILAYAHAN SECARA UMUM}

\begin{tabular}{|l|}
\hline IIII Kecamatan : ANDIR \\
Data Kewilayahan \\
Produk Unggulan \\
Potensi Kewilayahan Secara Umum \\
\hline Memliki sentra pasar tradisional dan modern \\
\hline Terdapat wisata China Town \\
\hline Terdapat Berbagai Macam Kelompok Seni \\
\hline Terdapat Berbagai Macam Kelompok Seni \\
\hline Sudah ada Program Pengembangan kewirausahaan, tetapi belum terimplementasi sempurna \\
\hline Kebutuhan Program/ Kegiatan yang mendukung untuk peningkatan \\
\hline
\end{tabular}

Gambar 3

Potensi Kewilayahan Secara Umum 


\section{d. KEBUTUHAN PROGRAM / KEGIATAN YANG MENDUKUNG UNTUK PENINGKATAN}

\begin{tabular}{|l|}
\hline IIII Kecamatan : ANDIR \\
Data Kewilayahan \\
Produk Unggulan \\
Potensi Kewilayahan Secara Umum \\
Kebutuhan Program/ Kegiatan yang mendukung untuk peningkatan \\
\hline Pelatihan untuk wirausaha mandiri \\
\hline Pemberian kemudahan akses permodalan dan pemasaran \\
\hline Pendampingan UMKM \\
\hline Wadah untuk sharing dan diskusi produk \\
\hline
\end{tabular}

Gambar 4

Kebutuhan Program yang Mendukung Peningkatan

\section{RANCANGAN BASIS DATA}

Basis data yang perlu dipersiapkan untuk kebutuhan informasi potensi kewilayahannya adalah :

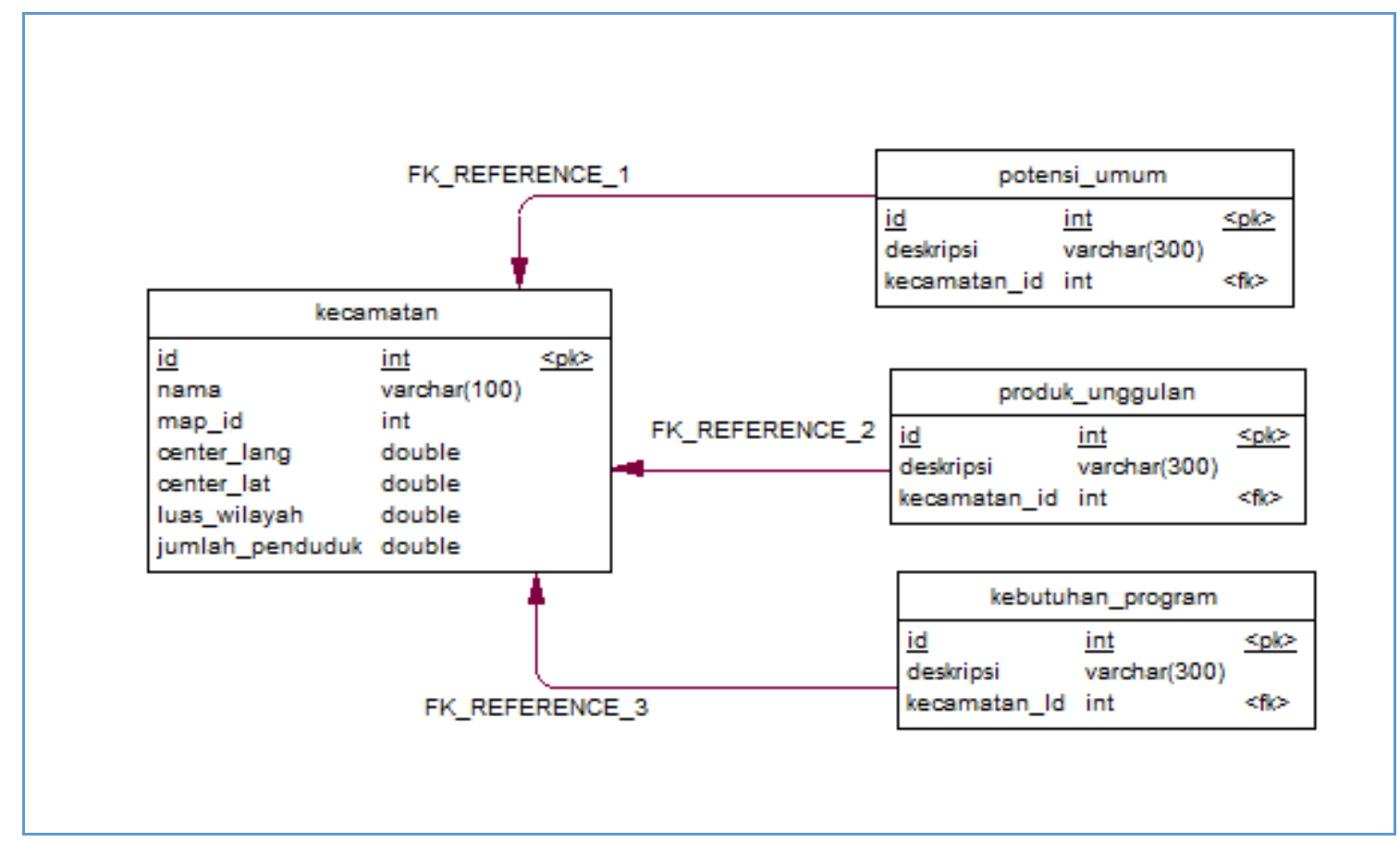

Gambar 5

Rancangan Skema Basis Data 


\section{KESIMPULAN}

Dengan adanya sistem informasi pemetaan potensi ekonomi kewilayahan di kota Bandung ini diharapkan bisa membantu program daerah dalam meningkatkan perkonomian di wilayahnya Dan juga menjadi sumber informasi bagi masyarakat umum untuk mengetahui potensi ekonomi dari sebuah kecamatan tertentu di kota Bandung.

\section{DAFTAR PUSTAKA}

[1] BPS Kota Bandung, 2017, Potensi Ekonomi Kota Bandung : Sensus Ekonomi 2016 Analisis Hasil Listing, ISBN : 978-602-70996-9-2

[2] Keneth \& Julie E. Kendall, 2008, System Analysis and Design Seventh Edition, Pearson/Prentice Hall 